\title{
Ceramics for Molten Materials Containment, Transfer and Handling on the Lunar Surface
}

\author{
Evan Standish ${ }^{1}$ and Doru M. Stefanescu ${ }^{2}$ \\ The Ohio State University, Columbus, Ohio, USA \\ Peter A. Curreri ${ }^{3}$ \\ NASA Marshall Space Flight Center, Huntsville, Alabama, USA
}

\begin{abstract}
As part of a project on Molten Materials Transfer and Handling on the Lunar Surface, molten materials containment samples of various ceramics were tested to determine their performance in contact with a melt of lunar regolith simulant. The test temperature was $1600{ }^{\circ} \mathrm{C}$ with contact times ranging from 0 to 12 hours. Regolith simulant was pressed into cylinders with the approximate dimensions of $1.25 \mathrm{dia} . \mathrm{x} 1.25 \mathrm{~cm}$ height and then melted on ceramic substrates. The regolith-ceramic interface was examined after processing to determine the melt/ceramic interaction.

It was found that the molten regolith wetted all oxide ceramics tested extremely well which resulted in chemical reaction between the materials in each case. Alumina substrates were identified which withstood contact at the operating temperature of a molten regolith electrolysis cell $\left(1600^{\circ} \mathrm{C}\right)$ for eight hours with little interaction or deformation. This represents an improvement over alumina grades currently in use and will provide a lifetime adequate for electrolysis experiments lasting 24 hours or more. Two types of non-oxide ceramics were also tested. It was found that they interacted to a limited degree with the melt resulting in little corrosion. These ceramics, $\mathrm{SiC}$ and $\mathrm{BN}$, were not wetted as well as the oxides by the melt, and so remain possible materials for molten regolith handling. Tests using longer holding periods and larger volumes of regolith are necessary to determine the ultimate performance of the tested ceramics.
\end{abstract}

\section{Background and Objectives}

Electrolytic reduction processes as a means to provide pure elements for lunar resource utilization have many advantages. Such processes have the potential of removing all the oxygen from the lunar soil for use in life support and for propellant. Electrochemical reduction also provides a direct path for the production of pure metals and silicon which can be utilized for in situ manufacturing and power production. This process is described fully by Curreri et al, ${ }^{i}$ but can be summarized as electrochemically

\footnotetext{
'Graduate student, Materials Science and Engineering,

${ }_{3}^{2}$ Ashland Research Professor, Materials Science and Engineering,

${ }^{3}$ Lead Project Scientist
} 
reducing a molten mixture of oxides to produce oxygen gas, a metal alloy, and a waste slag of unreduced oxides.

Some of the challenges encountered in the electrolytic reduction processes include the feeding of the electrolytic cell (the transfer of electrolyte containing lunar soil), the withdrawal of reactants and refined products such as the liquid iron-silicon alloy with a number of impurities, and the spent regolith slag, produced in the hot electrolytic cell for the reduction of lunar regolith. The materials that are fed to the cell may include gasses and solid (regolith, electrodes, electrolyte) materials.

The objective of this work is twofold;

- to design, execute and demonstrate a molten materials withdrawal device

- to determine appropriate materials for the containment of molten regolith electrolysis products and reactants.

If gasses will be introduced in the cell, pipes with one-way valves (vacuum-to pressurized feeding) can be used. For solid materials hoppers with screw mechanism (Figure 1) can be used for batch or continuous feeding. The screw mechanism could be designed such as to also insulate the pressurized space in the cell from the lunar vacuum. Alternatively, top charging as typically done in steel melting in electric-arc furnaces can be used (for details see next section). However, this will require the construction of an intermediate chamber for pressure equalization.

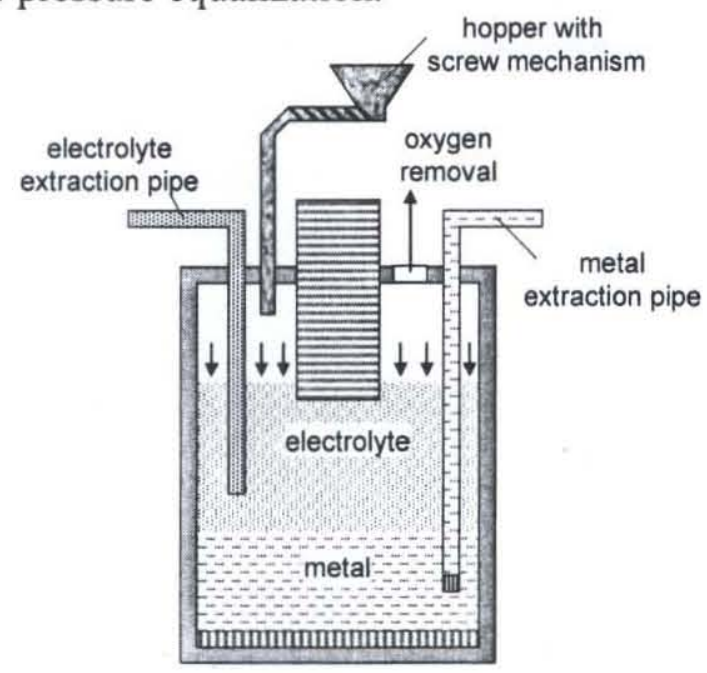

Figure 1. Schematic representation of an electrolytic cell with a screw feeding mechanism for solids.

In the case of lunar regolith the chemical composition of oxides charged into the furnace is described in Table 1. Based upon the composition of the regolith to be reduced and their various reduction potentials it is expected that the process should generate three metallic components, silicon, iron and a small amount of sodium. ${ }^{\text {ii }}$ After reduction of the metallic components, approximately $50 \%$ of the initial charge will remain as a slag to be removed and disposed of. For various reasons, the optimum process temperature for regolith electrolysis has been determined to be $1600^{\circ} \mathrm{C}$. ii The process then requires a material which can handle exposure to three distinctly different substances: a glassy silicate melt, a molten iron-silicon alloy, and high temperature oxygen gas. As materials for handling ferrosilicon are widely used in the steelmaking industry, this report will focus on the containment of the oxide melt in an oxidizing atmosphere. 
Table 1. Chemical composition (major components) of lunar regolith. iii

\begin{tabular}{lccc}
\hline Material & $\begin{array}{c}\text { JSC-1 } \\
\text { (mean of 3) }\end{array}$ & \multicolumn{2}{c}{$\begin{array}{c}\text { Lunar Soil } \\
14163^{*}\end{array}$} \\
\hline Oxide & $\begin{array}{c}\text { Concentration Std. Dev. } \\
\text { Wt \% }\end{array}$ & $\begin{array}{c}\text { Concentration } \\
\text { Wt \% }\end{array}$ & Wt \% \\
\hline $\mathrm{SiO}_{2}$ & 47.71 & 0.1 & 47.3 \\
$\mathrm{TiO}_{2}$ & 1.59 & 0.01 & 1.6 \\
$\mathrm{Al}_{2} \mathrm{O}_{3}$ & 15.02 & 0.04 & 17.8 \\
$\mathrm{Fe}_{2} \mathrm{O}_{3}$ & 3.44 & 0.03 & 0 \\
$\mathrm{FeO}_{\mathrm{MgO}}$ & 7.35 & 0.05 & 10.5 \\
$\mathrm{CaO}_{\mathrm{NaO}}$ & 9.01 & 0.09 & 9.6 \\
$\mathrm{Na}_{2} \mathrm{O}$ & 10.42 & 0.03 & 11.4 \\
$\mathrm{~K}_{2} \mathrm{O}$ & 2.7 & 0.03 & 0.7 \\
$\mathrm{MnO}_{\mathrm{Cr}}$ & 0.82 & 0.02 & 0.6 \\
$\mathrm{Cr}_{2} \mathrm{O}_{3}$ & 0.18 & 0 & 0.1 \\
$\mathrm{P}_{2} \mathrm{O}_{5}$ & 0.04 & 0 & 0.2 \\
$\mathrm{LOI}$ & 0.66 & 0.01 & -- \\
\hline $\mathrm{Total}$ & 0.71 & 0.05 & -- \\
\hline $\mathrm{LOI}=$ Loss on ignition & 99.65 & & 99.8 \\
\hline iv & &
\end{tabular}

In developing a method for processing and handling components involved in molten regolith electrolysis it is necessary to determine a material which has limited interaction with the molten reactant and products at a temperature of $1600{ }^{\circ} \mathrm{C}$. This is a challenging proposition as the materials involved in the process are highly interactive with different containment materials. Given the temperatures involved, the two reasonable choices for containment are either ceramics or refractory metals such as tungsten or molybdenum. The use of the latter as a containment vessel however is excluded by the fact that one of the products of the electrolysis reaction is a molten iron-silicon alloy. The solubility of the refractory metals in iron will induce rapid dissolution and failure of the crucibles. Additionally, the refractory metals are known to oxidize readily at high temperatures, and exposure to the highly oxidizing environment predicted to exist in a molten regolith electrolysis cell would again rapidly destroy any metallic components. Accordingly this research will be focused on ceramics as containment materials.

\section{Oxide Ceramics}

Ceramics cover a wide range of materials with highly varying properties, being generally described as hard, brittle and possessing a high melting point. The two major classes of ceramics are oxides and non-oxides. Those in the oxide category are used in bulk in many industries and have been used since antiquity for applications requiring temperature resistance. The non-oxides, which include carbides, nitrides, and borides, are still being actively developed and are used primarily in high-tech applications in which their superior performance for specific applications outweighs their high cost.

Given their availability and relatively low cost, the first choice for ceramic containment equipment would be the oxide ceramics. However, because the electrolyte in molten regolith electrolysis is itself a mixture of molten oxides, it is questionable whether an 
oxide crucible would withstand the aggressive nature of the reactant for long periods of time. The major component of lunar regolith, silica, is regarded as a universal solvent of other oxides so it is likely that any oxide ceramics used will exhibit some solubility in the melt. Additionally, the many lower mass fraction components of lunar regolith provide the possibility of incompatibility with a wide range of candidate oxides. It is necessary therefore to determine a procedure for choosing the most likely candidates and to perform tests on these ceramic to prove their usability.

An obvious first criterion which must be met for this materials containment problem is the melting point of the ceramic. This however is not as easy as it seems, as the regolith electrolyte contains a mixture of many oxides, which results in the possibility of forming any number of low melting point eutectics with the containment material, a situation which would result in the rapid failure of the crucible. The determination of the low melting eutectics of the entire five component system would require analysis of a very complex phase diagram, which is not available. The data shown in Table 2 however can be used to give a rough picture of the possible results.

Table 2: Binary eutectics of various components of the potential regolith-crucible system $\left({ }^{\circ} \mathrm{C}\right) .{ }^{v}$

\begin{tabular}{lcccccc}
\hline & $\begin{array}{c}\text { Melting } \\
\text { Point }\end{array}$ & $\mathrm{Al}_{2} \mathrm{O}_{3}$ & $\mathrm{CaO}$ & $\mathrm{MgO}$ & $\mathrm{SiO}_{2}$ & $\mathrm{ZrO}_{2}$ \\
\hline $\mathrm{Al}_{2} \mathrm{O}_{3}$ & 2050 & $\mathrm{X}$ & 1360 & 1995 & 1546 & 1710 \\
$\mathrm{CaO}$ & 2610 & 1360 & $\mathrm{X}$ & 2300 & 1436 & 2140 \\
$\mathrm{FeO}$ & 1370 & 1310 & $\mathrm{X}$ & $\mathrm{X}$ & $\mathrm{X}$ & $\mathrm{X}$ \\
$\mathrm{MgO}$ & 2850 & 1995 & 2300 & $\mathrm{X}$ & 1543 & 2113 \\
$\mathrm{SiO}_{2}$ & 1710 & 1546 & 1436 & 1543 & $\mathrm{X}$ & 1675 \\
$\mathrm{TiO}_{2}$ & 1840 & 1750 & 1420 & 1600 & 1540 & 1750 \\
\hline
\end{tabular}

The only common oxide material which does not form binary eutectics below the process temperature with any of the regolith components is zirconium oxide. However, zirconium oxide undergoes a phase transformation at $1170{ }^{\circ} \mathrm{C}$ which necessitates the inclusion of a stabilizing additive (often magnesium, yttrium, or calcium oxides), potentially resulting in decreased performance of the ceramic.

Aluminum oxide is a standard material for high temperature use. In a pure form, it is inert to many materials at high temperature and is therefore used in applications requiring high temperature corrosion resistance. It is also relatively inexpensive, which makes it an attractive material for consideration.

A second ceramic material which has been known to exhibit good corrosion resistance, especially towards silicate melts, is aluminum oxide containing a high percentage of chromium oxide. These materials are used extensively in the glass industry for containment of a variety of glasses and have been shown to exhibit superior corrosion resistance to glass compositions of similar compositions near the same processing temperatures ${ }^{\text {viviii }}$ These materials are also used for lining waste incinerators as they have been shown to exhibit good corrosion resistance to the multi component systems developed in these environments. ${ }^{\text {viii,ix }}$

The detrimental effect of possible eutectic formation is not a guaranteed result. While a eutectic may form at equilibrium, the liquid could become saturated and stop dissolving the crucible or dissolution may be limited by lack of agitation of the melt. It is necessary 
therefore to run tests on ceramics under simulated process conditions to determine whether they experience corrosion or withstand exposure to the molten regolith.

\section{Non-Oxide Ceramics}

Non-oxide ceramics are based upon systems of carbides, nitrides and borides. These ceramics are generally known to possess good corrosion resistance, as well as extreme heat resistance, some up to temperatures of well over $3000^{\circ} \mathrm{C}^{\mathrm{x}}$. Ceramics with temperature capability in this range, however, are still under development. The most commonly used non-oxides include silicon carbide, silicon nitride and boron nitride. These materials find use in applications requiring high hardness and temperature resistance. The major potential advantage non-oxide ceramics provide for this application is that many are not wetted by either molten metals or oxides ${ }^{\mathrm{xi}}$. This characteristic is advantageous because it limits the interactions which take place between ceramic and slag/metal, meaning they have a high degree of corrosion resistance to both classes of material.

The main drawback to the use of non-oxides in this application is the fact that all of the commonly available non-oxide ceramics have limited use in oxidizing environments. Maximum recommended temperature for many non-oxides is under $1000^{\circ} \mathrm{C}$, far below the $1600{ }^{\circ} \mathrm{C}$ processing temperature required for molten regolith electrolysis. However, some non-oxide ceramics have the ability to form protective coatings against oxidation depending on the environment. Ceramics such as $\mathrm{SiC}, \mathrm{MoSi}_{2}$, and $\mathrm{Si}_{3} \mathrm{~N}_{4}$ are able to form silicon dioxide glass coatings which prevent diffusion of oxygen into the bulk of the material, thus preventing oxidation ${ }^{\text {xii }}$. The formation of a protective coating however, may be adversely influenced by the interaction with the oxide melt, which has the potential to dissolve any glassy coatings forming on the surface of a ceramic. Additionally, the non-oxide ceramics is the fact that they are expensive, and therefore are not manufactured in a wide range of products. Lack of availability then is a major obstacle to the use of many advanced non-oxides which at first glance might be potential candidates. The two non-oxide ceramics most commonly used in the temperature range desired are silicon carbide and boron nitride. The melting/sublimation points of these materials are around $2700{ }^{\circ} \mathrm{C}$ and they are readily available from several manufacturers, therefore investigation into these ceramics was considered before other non-oxides. 


\section{Design of the Molten Materials Withdrawal Device}
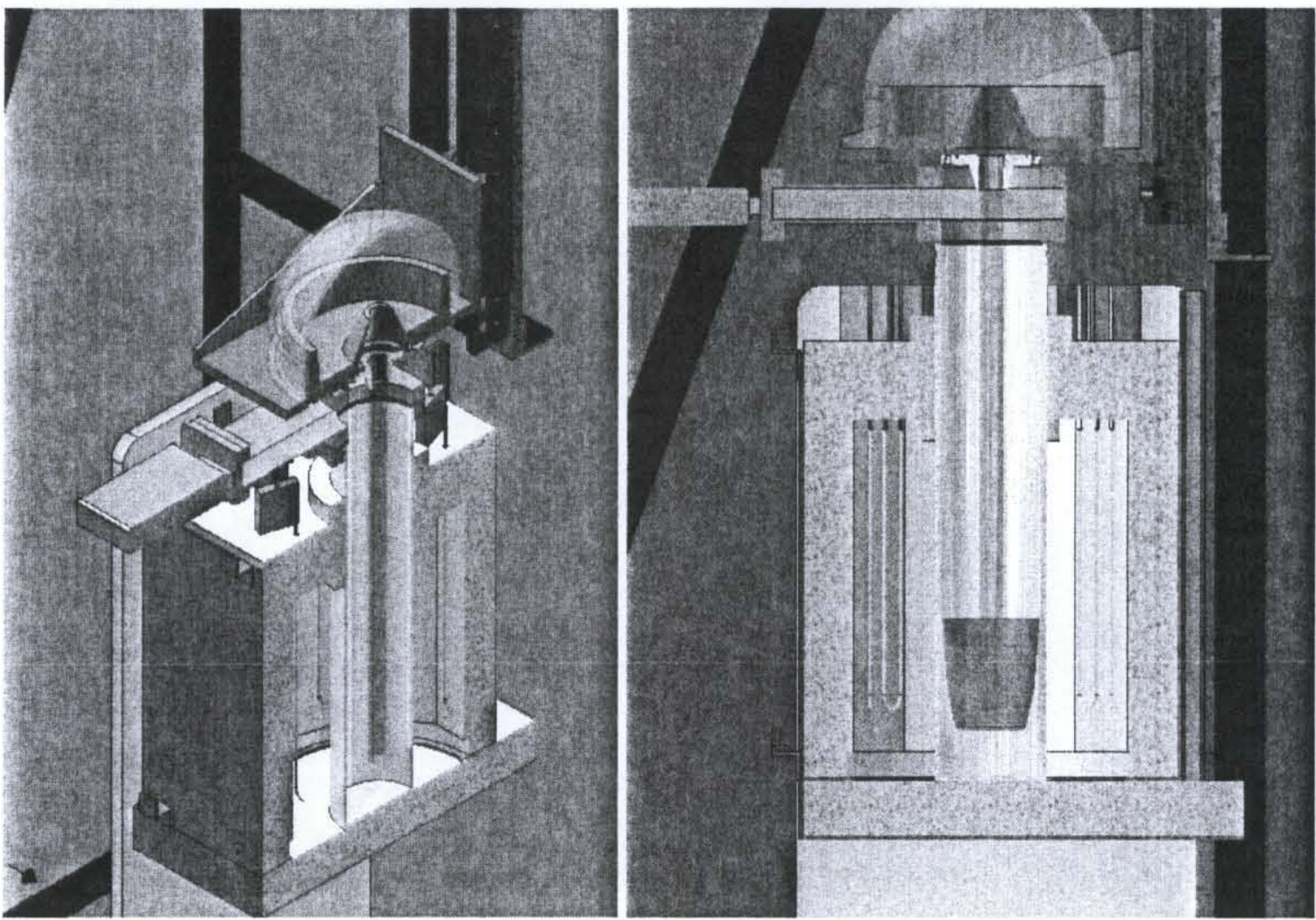

The pictures above show the proposed system in fully lowered position. The crucible is elevated slightly in the furnace tube by a refractory block so as to keep it in the hottest part of the furnace and reduce the distance the fluid needs to travel in the withdrawal tube. The furnace tube is closed off with a flange which is sealed with two o-rings. This flange is in turn bolted to a slide gate valve which provides atmospheric containment. The reliability of this slide gate is not established and is an area requiring further exploration.

\section{Experimental Procedure}

Experiments for determining the corrosion resistance of various ceramics were conducted using small samples of ceramic in spot contact tests with molten regolith. Ceramic samples were obtained from various suppliers and are listed in Table 3.

Table 3. List of tested materials.

\begin{tabular}{cll}
\hline Sample\# & Material Description & \multicolumn{1}{c}{ Comments } \\
\hline 1 & Alumina & $99.6 \%$ \\
2 & Alumina & $99.8 \%$ \\
3 & Alumina & $99.8 \%$ \\
4 & Alumina & $99.8 \%$ \\
5 & Zirconia & MgO stabilized (open porosity) \\
6 & Zirconia & CaO stabilized \\
7 & Zirconia & $10.5 \%$ Yttria stabilized \\
8 & Magnesia & refractory (open porosity)
\end{tabular}




$\begin{array}{cll}9 & \text { Magnesia } & 4.5 \% \text { closed porosity } \\ 10 & \text { Alumina+30\%Chromia } & \text { (16\% closed porosity) } \\ 11 & \text { Boron Nitride } & \text { Hot Pressed } \\ 12 & \text { Boron Nitride } & \text { Hot Pressed, } 5 \% \text { CaO Binder } \\ 13 & \text { Silicon Carbide } & \text { Alpha phase, pressureless sintered } \\ 14 & \text { Silicon Carbide } & \text { P. A. D. (hot pressed) }\end{array}$

A series of tests was conducted to determine the compatibility of the listed ceramics with the molten lunar regolith simulant JSC-1 which was supplied by Marshall Space Flight Center. All following references to regolith imply this simulant. Ceramic samples were cut and placed in a secondary containment vessel made of $99.6 \%$ alumina. Samples of pressed simulant powder were placed on top of the ceramics for spot contact corrosion testing. In order to facilitate easier handling and measurement, powdered stimulant was pressed into cylinders measuring approximately $1 \mathrm{~cm}$ in diameter with a range of lengths to give variable total powder sample weights. These samples ranged in weight from 1 to 3.5 grams depending on the size of ceramic to be tested. It was desired to maintain a constant contact area between ceramic substrates and the regolith simulant melt. However, because the supplied ceramics were of different geometries the sample cut for testing were of non uniform size. To attempt to standardize the volume of regolith above a given surface area, and therefore eliminate bias based upon the differing dissolvable weights of substrate components, regolith powder weight was adjusted for samples of differing size.

After covering the containment vessel with another plate of $99.6 \%$ alumina, the entire vessel was loaded into an electrically heated box furnace and brought to a temperature of $1600^{\circ} \mathrm{C}$ for varying test times. The ramp rate for heating and cooling was set to $5^{\circ} \mathrm{C}$ per minute to minimize the chance of thermal shock damaging either the test substrates or the containment vessel. Time at temperature was varied to examine how corrosion progressed over time. Because the oxide mixture melts at approximately $1140^{\circ} \mathrm{C}$, at a $5^{\circ} \mathrm{C}$ per minute ramp rate the ceramics were exposed to molten regolith for approximately 3 hours total during the heating and cooling cycles. Because corrosion reactions can be highly temperature dependant though, this transitory exposure is of less importance than exposure at the $1600^{\circ} \mathrm{C}$ target temperature.

Different atmospheres were used to examine the effects of oxygen partial pressure on corrosion of the ceramics and oxidation of the non-oxide ceramics. Given that operating conditions for an electrolysis cell at production scale will likely be highly oxidizing, the majority of tests were conducted in an air atmosphere

A section view of a typical experimental setup is shown in Figure 2. 


\section{Resistance Heated Box Furnace}

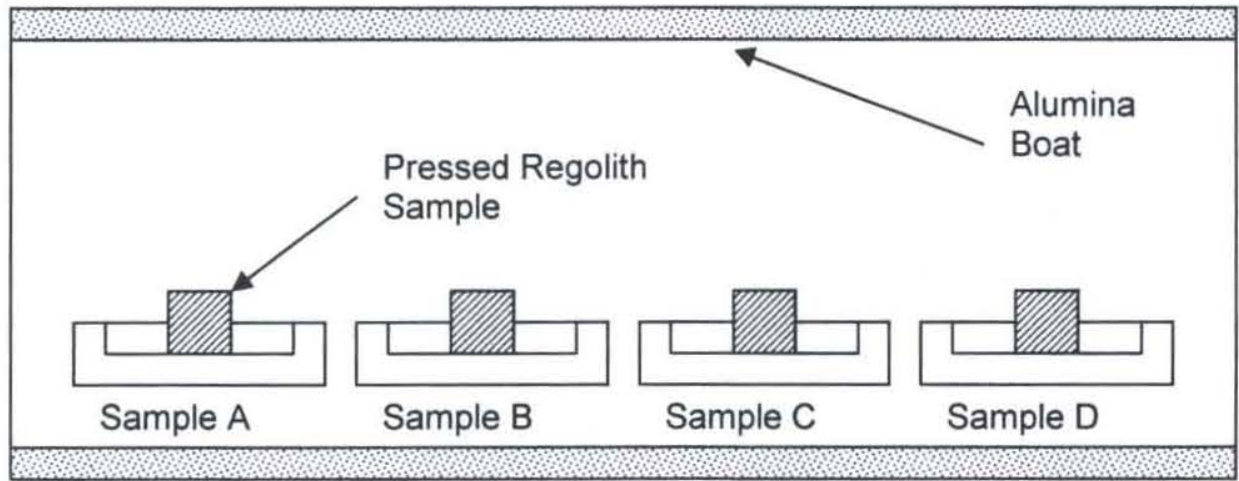

Figure 2. Typical Experimental setup

After cooling, the ceramic samples were cut, mounted and polished for optical and electron microscopy observations.

\section{Experimental Results}

Results of various tests are shown in the following figures. Test conditions are described for each figure.

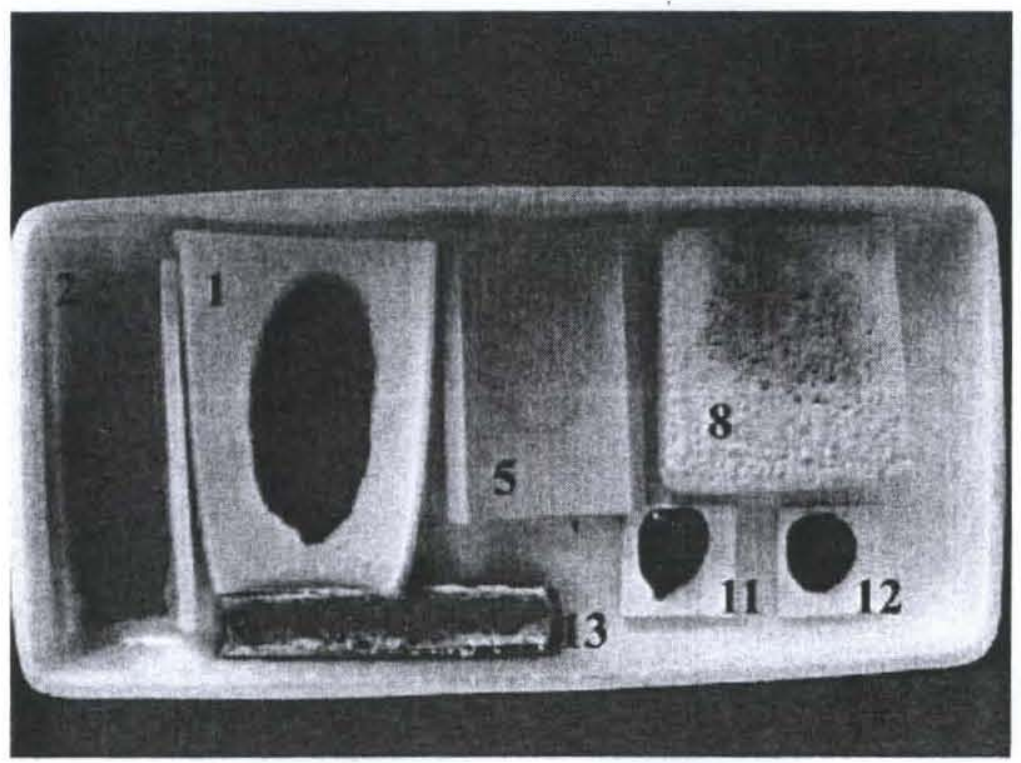

Figure 3. Photograph of several ceramics after removal from furnace. Sample numbers correspond to products listed in Table 3. Time at temp: $6 \mathrm{hr}$, atmosphere: air. 


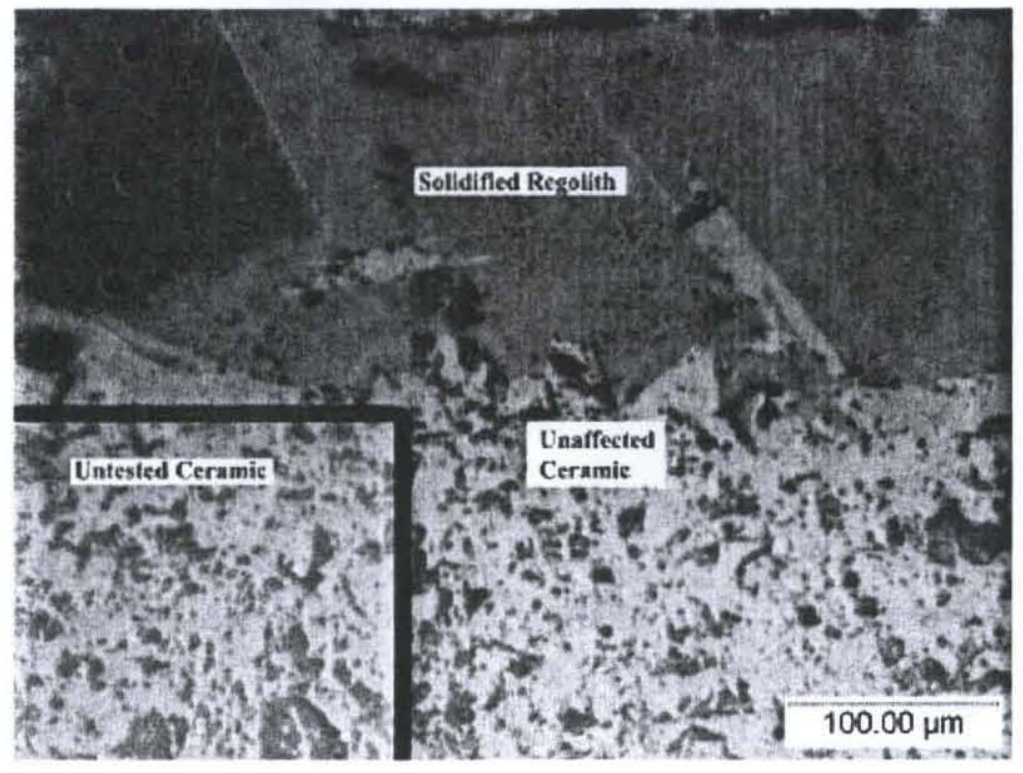

Figure 4. Optical micrograph of sample \#1, 99.6\% alumina. Time at temp: $8 \mathrm{hr}$, atmosphere: air. Inset is untested ceramic of same material for comparison.

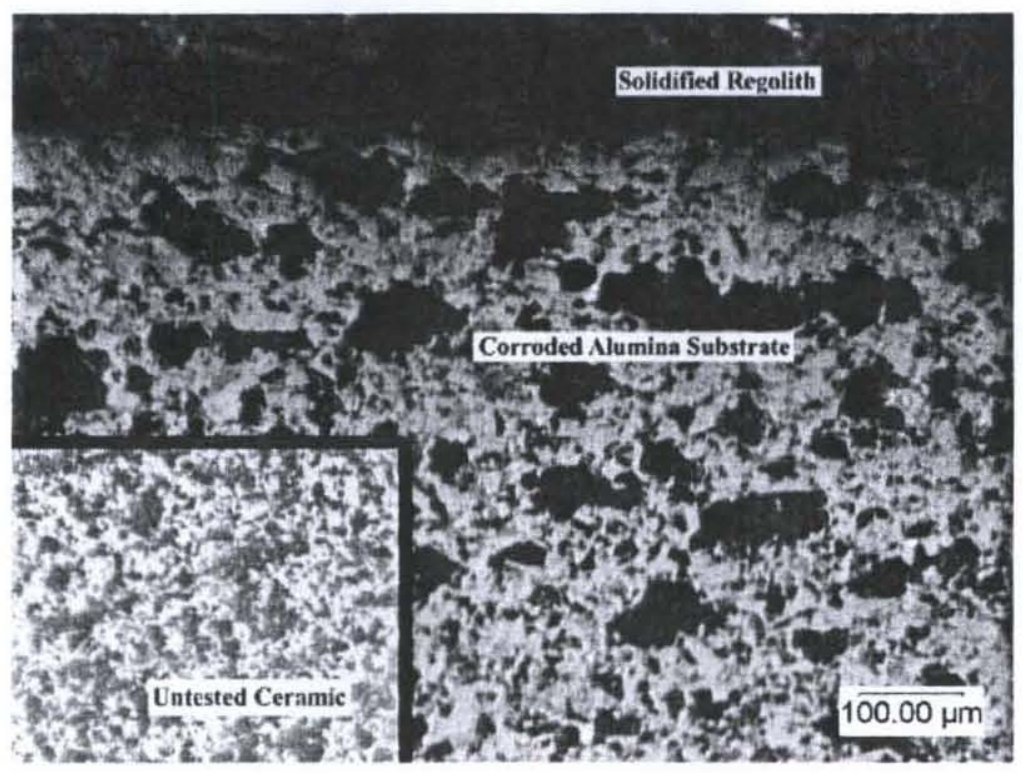

Figure 5. Optical micrograph of sample $\# 3,99.8 \%$ alumina. Time at temp: $8 \mathrm{hr}$, atmosphere: air. The other alumina samples $(\# 2,4)$ all had similar performance in terms of microstructural changes and all exhibited solubility at the melt/substrate interface. 


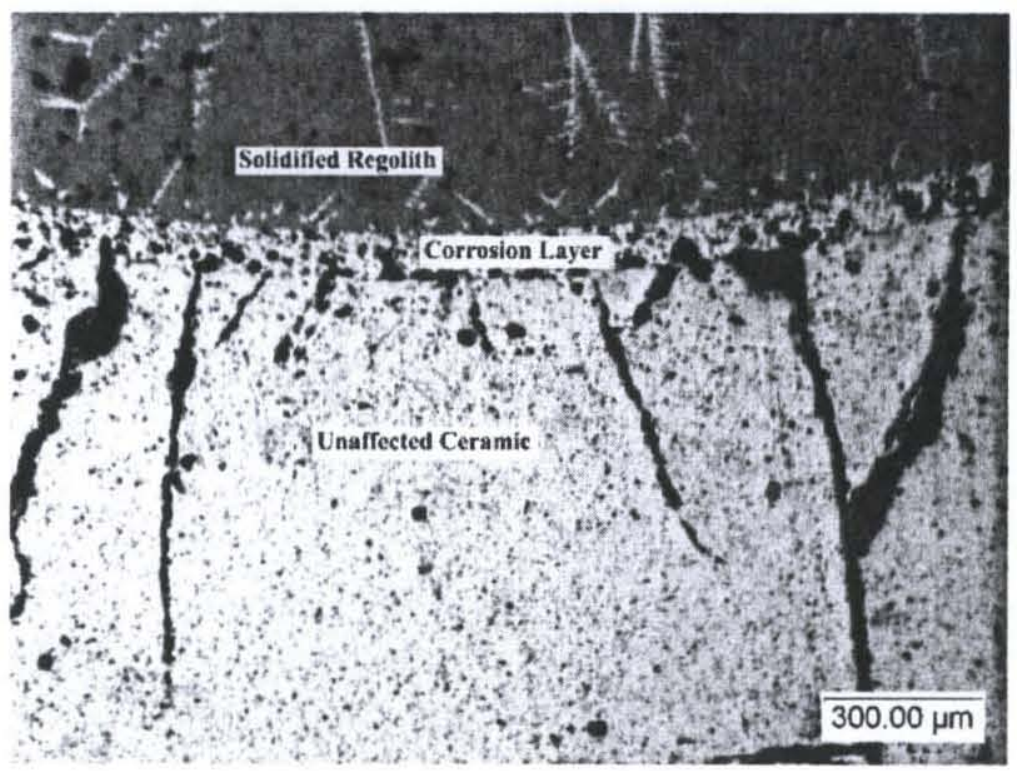

Figure 6. Optical micrograph of sample \#7 Yttrium stabilized zirconia. Time at temp: $6 \mathrm{hr}$, atmosphere: air.

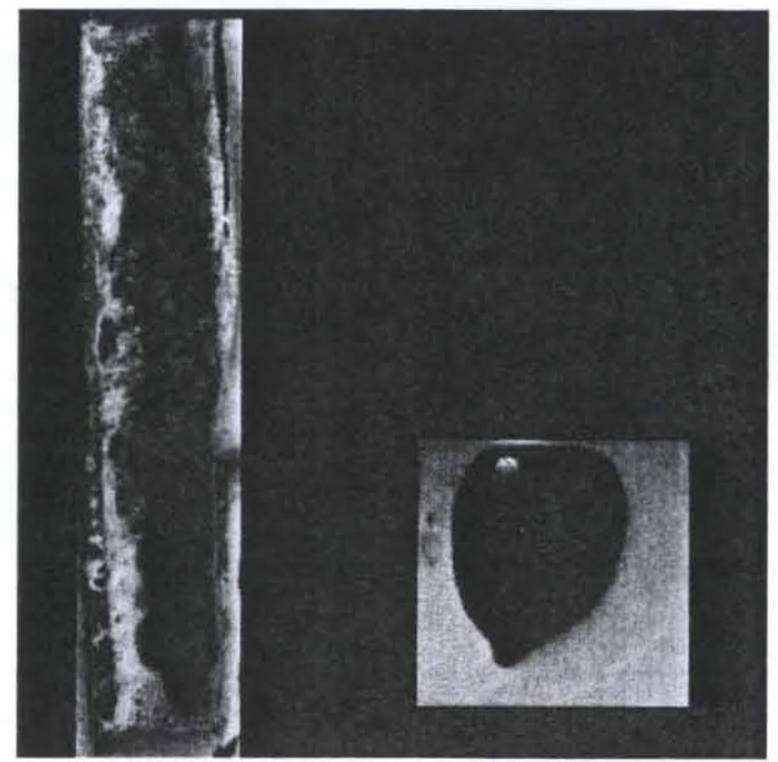

Figure 7. Silicon carbide and boron nitride after removal from furnace. Time at temp: $6 \mathrm{hr}$, atmosphere: air. 


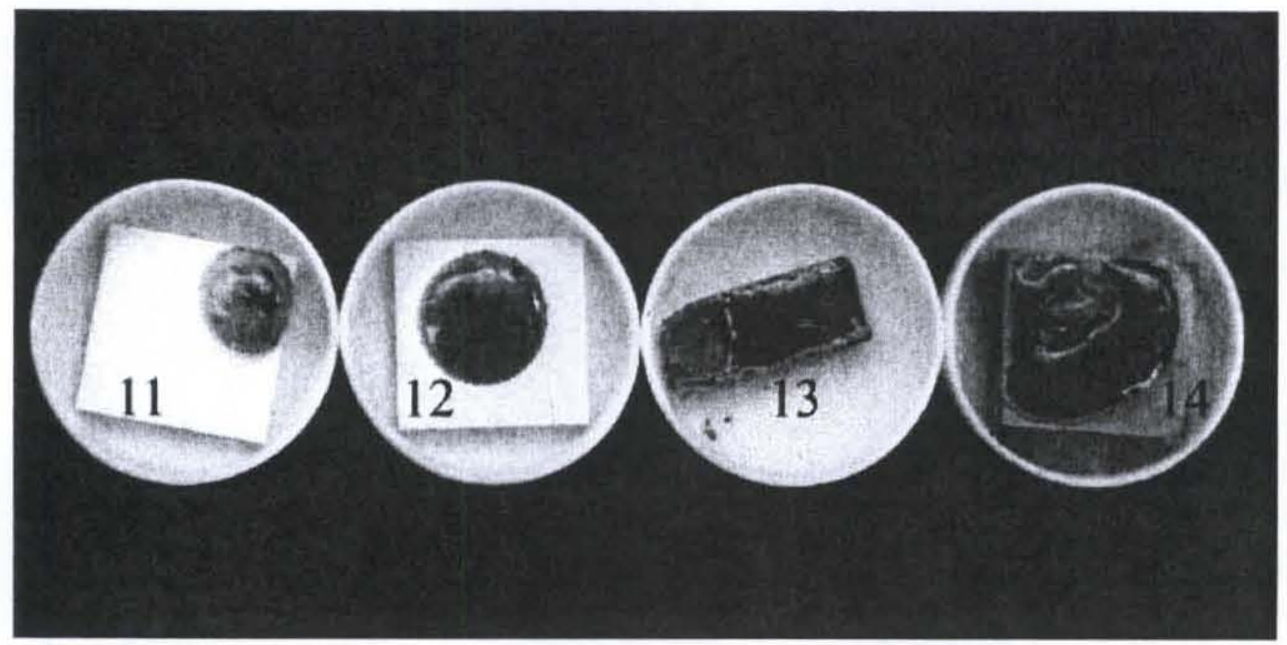

Figure 8. Boron nitride and silicon carbide after removal from furnace. Time at temp: heating to/cooling from $1600^{\circ} \mathrm{C}$, no holding, atmosphere: argon.

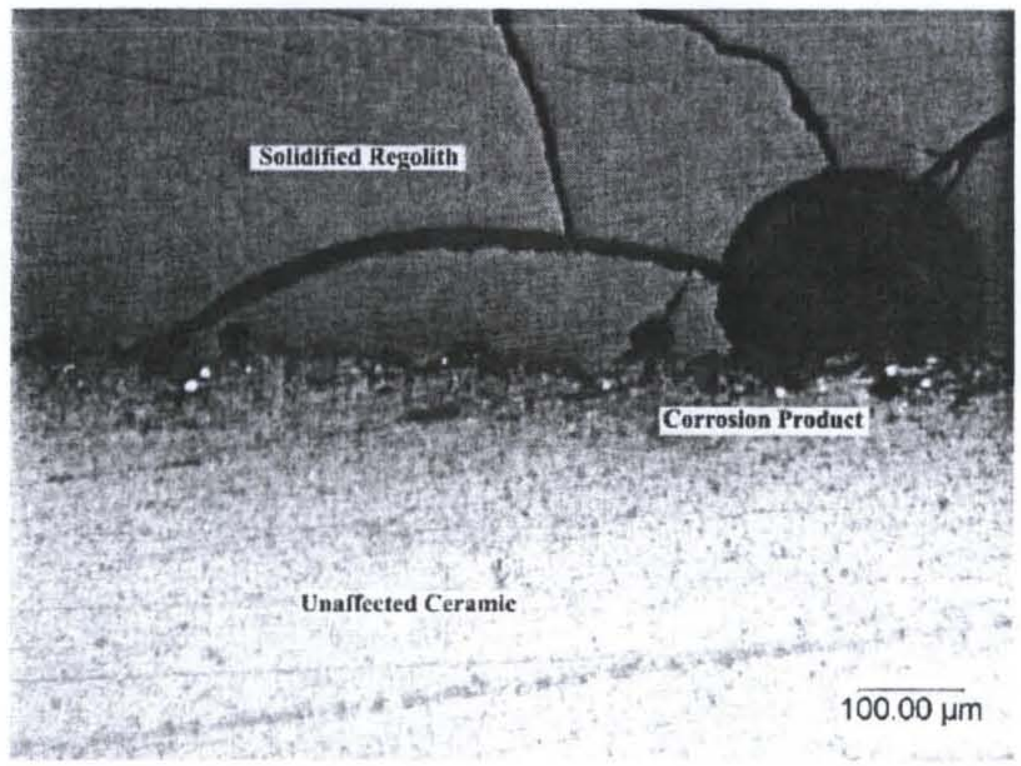

Figure 9. Optical micrograph of sample \#11, binderless hot pressed boron nitride. Time at temp: 6 hr, atmosphere: air. A small amount of corrosion product is visible as white dots near the meltsubstrate interface. This is a reaction product from the reduction of iron in the regolith by the boron nitride. Maximum depth of reaction was $56 \mu \mathrm{m}$. 


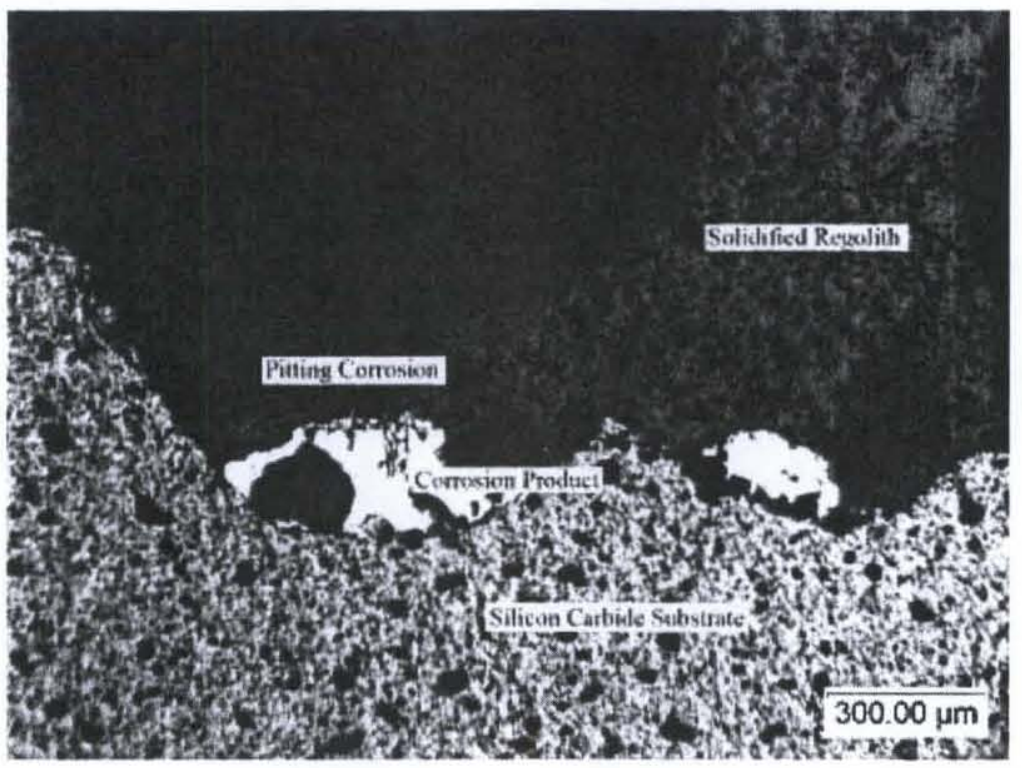

Figure 10. Optical micrograph of sample \#13, pressureless sintered SiC. Time at temp: $6 \mathrm{hr}$, atmosphere: air. Maximum depth of corrosion is approximately $360 \mu \mathrm{m}$.

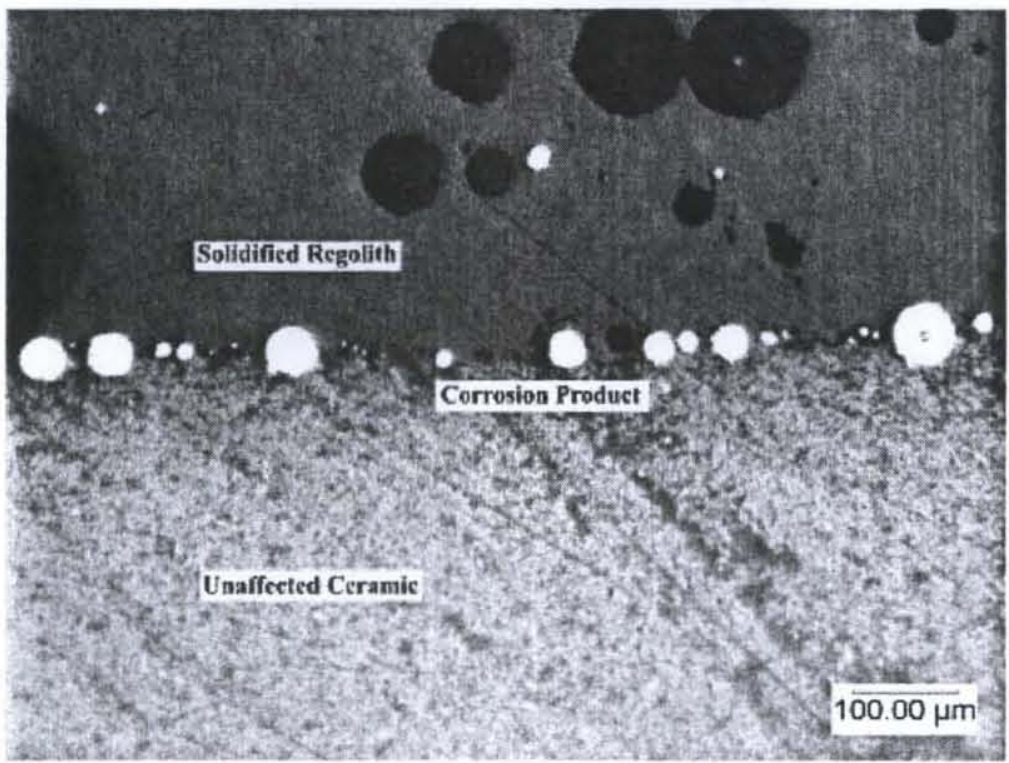

Figure 11. Optical micrograph of sample \#11, binderless hot pressed boron nitride. Time at temp: transitory exposure only, atmosphere: argon. Considerably more of the reduced iron (white spheres) is visible in tests run in argon. The penetration distance into the ceramic however is very small, $35 \mu \mathrm{m}$. 


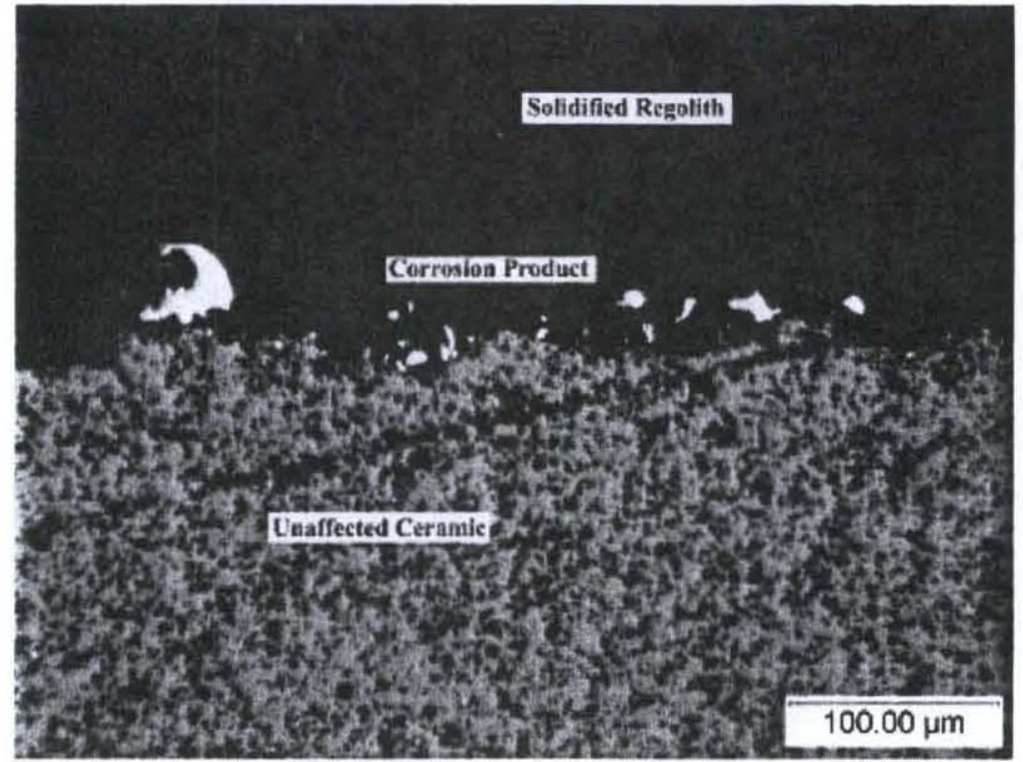

Figure 12. Optical micrograph of sample \#13, pressureless sintered SiC. Time at temp: heating to/cooling from $1600^{\circ} \mathrm{C}$, no holding, atmosphere: argon. Corrosion is again visible to a maximum depth of $65 \mu \mathrm{m}$.

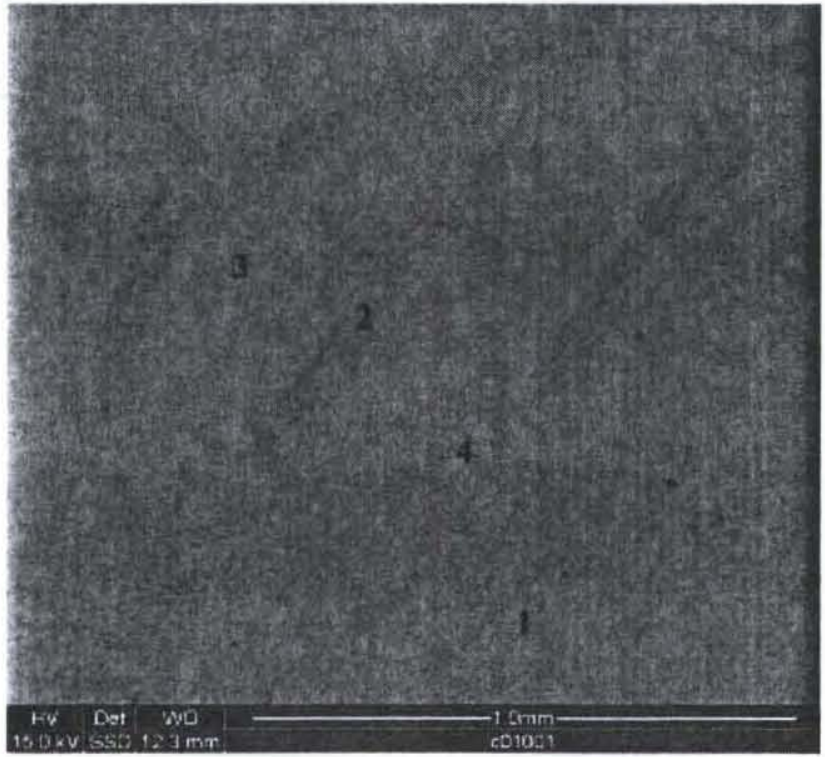

Figure 13. SEM micrograph of sample \#1 $99.6 \%$ alumina. Time at temp: $12 \mathrm{hr}$, atmosphere: air. Two phases are present in the solidified regolith, but the substrate does not contain any reaction products. Marked locations were scanned for composition, results are shown in Table $\mathbf{4}$ and Table 5. The sample was coated with carbon prior to microscopy to avoid specimen charging.

Table 4. EDS results for sample \#1.

\begin{tabular}{ccccccccc}
\hline \multirow{2}{*}{ Element } & \multicolumn{2}{c}{ Scan 1 } & \multicolumn{2}{c}{ Scan 2 } & \multicolumn{2}{c}{ Scan 3 } & \multicolumn{2}{c}{ Scan 4 } \\
& Wt \% & At \% & Wt \% & At \% & Wt \% & At \% & Wt \% & At \% \\
\hline $\mathbf{C}$ & 57.29 & 71.19 & 57.42 & 71.69 & 57.23 & 72.09 & 58.37 & 73.17 \\
$\mathbf{O}$ & 14.2 & 13.25 & 13.42 & 12.58 & 13.87 & 13.12 & 12.36 & 11.64 \\
$\mathrm{Na}$ & 0.05 & 0.04 & 0.04 & 0.03 & 0.27 & 0.18 & 0.36 & 0.23
\end{tabular}




\begin{tabular}{ccccccccc}
$\mathbf{M g}$ & 0.27 & 0.17 & 0.45 & 0.28 & 1.97 & 1.23 & 3.11 & 1.93 \\
$\mathbf{A l}$ & 26.45 & 14.63 & 24.17 & 13.43 & 11.07 & 6.21 & 10.85 & 6.05 \\
$\mathrm{Si}$ & 0.89 & 0.47 & 2.55 & 1.36 & 9.38 & 5.05 & 9.82 & 5.27 \\
$\mathrm{Ca}$ & 0.35 & 0.13 & 1 & 0.37 & 4.14 & 1.56 & 3.13 & 1.18 \\
$\mathbf{F e}$ & 0.49 & 0.13 & 0.96 & 0.26 & 2.07 & 0.56 & 2 & 0.54 \\
\hline Total & 100 & 100 & 100 & 100 & 100 & 100 & 100 & 100 \\
\hline
\end{tabular}

Table 5. EDS results for sample \#1 corrected for carbon coating.

\begin{tabular}{ccccccccc}
\hline \multirow{2}{*}{ Element } & \multicolumn{2}{c}{ Scan 1 } & \multicolumn{2}{c}{ Scan 2 } & \multicolumn{2}{c}{ Scan 3 } & \multicolumn{2}{c}{ Scan 4 } \\
& Wt \% & At \% & Wt \% & At \% & Wt \% & At \% & Wt \% & At \% \\
\hline $\mathbf{O}$ & 33.25 & 45.99 & 31.52 & 44.44 & 32.43 & 47.01 & 29.69 & 43.38 \\
$\mathbf{N a}$ & 0.12 & 0.14 & 0.09 & 0.11 & 0.63 & 0.64 & 0.86 & 0.86 \\
$\mathbf{M g}$ & 0.63 & 0.59 & 1.06 & 0.99 & 4.61 & 4.41 & 7.47 & 7.19 \\
$\mathbf{A l}$ & 61.93 & 50.78 & 56.76 & 47.44 & 25.88 & 22.25 & 26.06 & 22.55 \\
$\mathbf{S i}$ & 2.08 & 1.63 & 5.99 & 4.80 & 21.93 & 18.09 & 23.59 & 19.64 \\
$\mathbf{C a}$ & 0.82 & 0.45 & 2.35 & 1.31 & 9.68 & 5.59 & 7.52 & 4.40 \\
$\mathbf{F e}$ & 1.15 & 0.45 & 2.25 & 0.26 & 4.84 & 2.01 & 4.80 & 2.01 \\
\hline Total & 100 & 100 & 100 & 100 & 100 & 100 & 100 & 100 \\
\hline
\end{tabular}

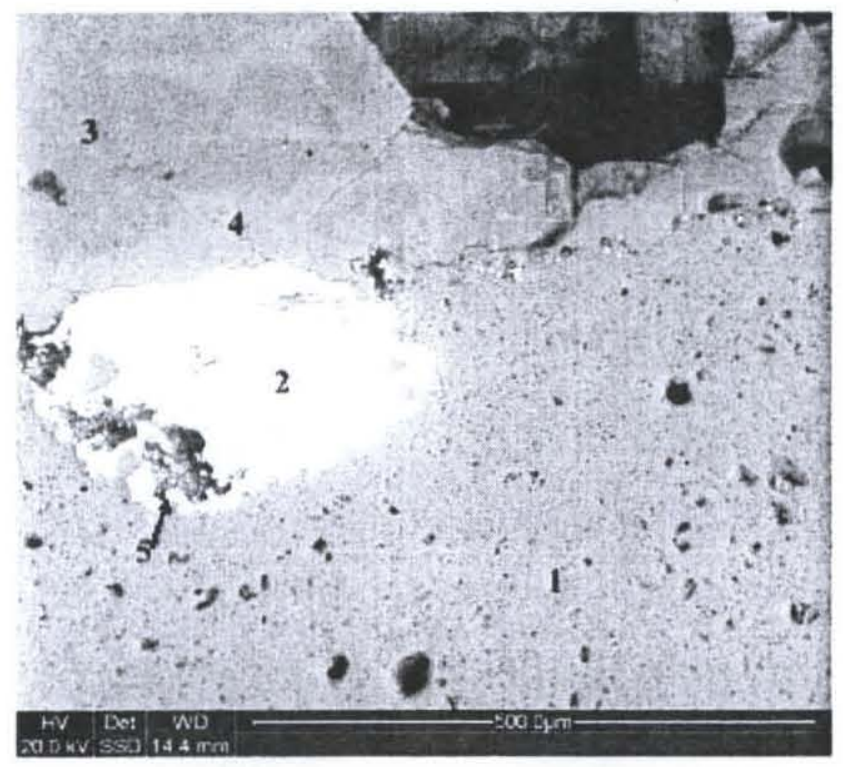

Figure 14. SEM micrograph of sample \#13 pressureless sintered silicon carbide. Time at temp: $8 \mathrm{hr}$, atmosphere: air. Two phases are present in the solidified regolith $(3,4)$, and there are two visible reaction products $(2,5)$. Marked locations were scanned for composition, results are shown in Table 6. The sample was uncoated. 
Table 6. EDS results for sample \#13.

\begin{tabular}{ccccccccccc}
\hline \multirow{2}{*}{ Element } & \multicolumn{2}{c}{ Scan 1 } & \multicolumn{3}{c}{ Scan 2 } & \multicolumn{2}{c}{ Scan 3 } & \multicolumn{2}{c}{ Scan 4 } & \multicolumn{2}{c}{ Scan 5 } \\
& Wt \% & At \% & Wt \% & At \% & Wt \% & At \% & Wt \% & At \% & Wt \% & At \% \\
\hline C & 37.15 & 58.02 & 13.83 & 34.01 & 14.26 & 22.38 & 11.99 & 18.86 & 66.22 & 80.83 \\
O & -- & -- & 6.08 & 11.22 & 37.27 & 43.92 & 44.42 & 52.43 & 11.82 & 10.83 \\
Mg & -- & -- & -- & -- & -- & - & 3.74 & 2.91 & 0.06 & 0.03 \\
Al & -- & -- & 2.20 & 2.40 & 41.75 & 29.18 & 12.86 & 9.00 & 0.84 & 0.46 \\
Si & 62.85 & 41.98 & 21.22 & 22.32 & 6.72 & 4.51 & 21.81 & 14.67 & 8.82 & 4.60 \\
Ca & -- & -- & -- & -- & -- & -- & 2.87 & 1.35 & 0.28 & 0.10 \\
Cr & -- & -- & 1.64 & 0.93 & -- & -- & - & -- & -- & - \\
Mn & -- & -- & 0.19 & 0.10 & -- & -- & - & -- & - & - \\
Fe & -- & -- & 54.86 & 29.02 & -- & -- & 2.31 & 0.78 & 11.96 & 3.14 \\
\hline Total & 100 & 100 & 100 & 100 & 100 & 100 & 100 & 100 & 100 & 100 \\
\hline
\end{tabular}

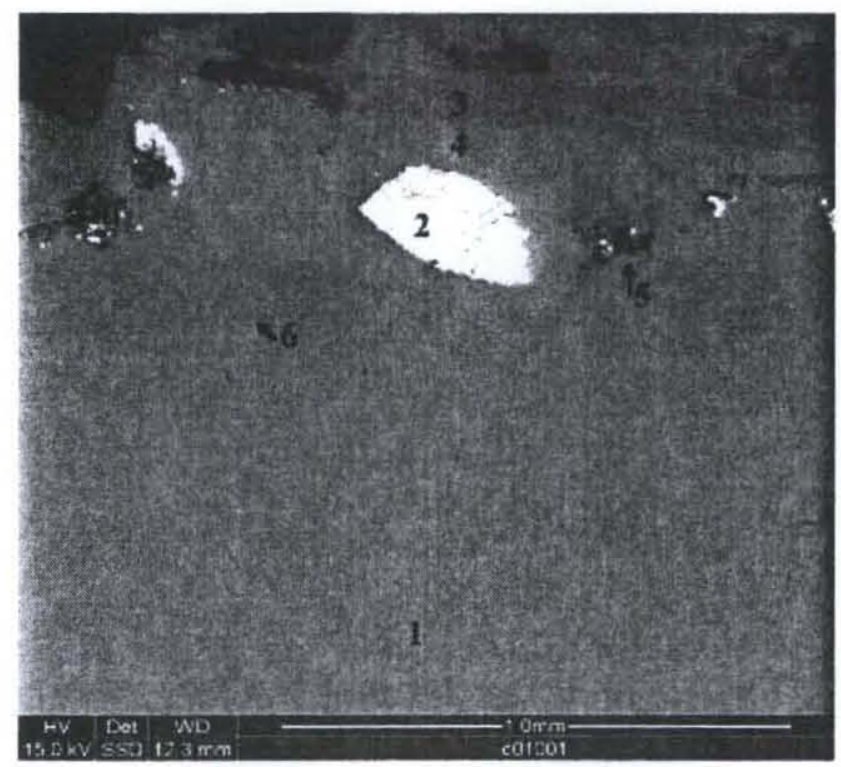

Figure 15. SEM micrograph of sample \#14 silicon carbide. Time at temp: $8 \mathrm{hr}$, atmosphere: air. Marked locations were scanned for composition, results are shown in Table 7. The sample was uncoated.

Table 7. EDS results for sample \#14.

\begin{tabular}{c|cccccccccccc}
\hline \multirow{2}{*}{ Element } & \multicolumn{2}{c}{ Scan 1 } & \multicolumn{2}{c}{ Scan 2 } & \multicolumn{2}{c}{ Scan 3 } & \multicolumn{2}{c}{ Scan 4 } & \multicolumn{2}{c}{ Scan 5 } & \multicolumn{2}{c}{ Scan 6 } \\
& Wt \% & At \% & Wt \% & At \% & Wt \% & At \% & Wt \% & At \% & Wt \% & At \% & Wt \% & At \% \\
\hline C & 27.6 & 46.7 & 11.2 & 29.69 & 16.35 & 25.5 & 12.41 & 19.18 & 72.07 & 81.77 & 12.33 & 20.64 \\
O & 2.2 & 2.8 & 5.73 & 11.4 & 34.9 & 40.86 & 45.05 & -52.24 & 12.86 & 10.95 & 29.22 & 36.71 \\
Mg & -- & -- & -- & -- & 0.49 & 0.38 & -- & -- & 0.52 & 0.29 & 0.31 & 0.25
\end{tabular}




\begin{tabular}{c|cccccccccccc} 
Al & 1.86 & 1.4 & 2.97 & 3.5 & 43.93 & 30.5 & 17.51 & 12.04 & 4.33 & 2.19 & 29.59 & 22.04 \\
$\mathbf{S i}$ & 67.33 & 48.71 & 16.84 & 19.08 & 3.74 & 2.49 & 25.03 & 16.53 & 9.08 & 4.41 & 28.25 & 20.22 \\
$\mathbf{C a}$ & -- & -- & -- & -- & 0.6 & 0.28 & -- & - & 1.15 & 0.39 & 0.3 & 0.15 \\
$\mathbf{P}$ & 0.05 & 0.03 & 0.48 & 0.49 & -- & -- & -- & - & -- & -- & -- & - \\
$\mathbf{C r}$ & 0.39 & 0.15 & 1.37 & 0.84 & -- & -- & -- & - & -- & - & - & - \\
$\mathbf{F e}$ & 0.56 & 0.2 & 61.42 & 35 & -- & -- & -- & - & -- & - & - & - \\
\hline Total & 100 & 100 & 100 & 100 & 100 & 100 & 100 & 100 & 100 & 100 & 100 & 100 \\
\hline
\end{tabular}

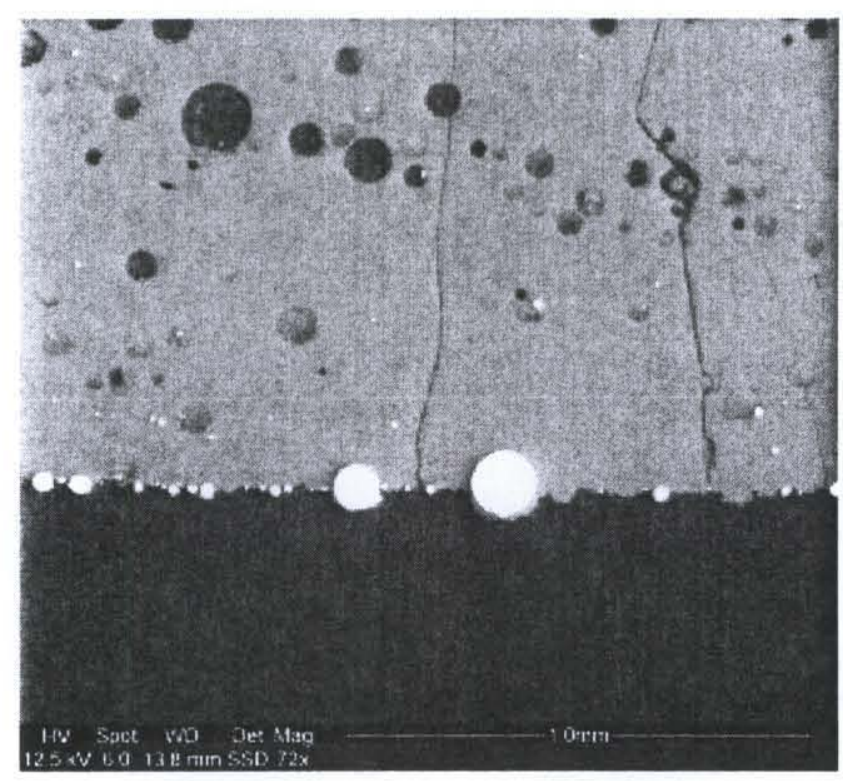

Figure 16. SEM micrograph of sample \#11 boron nitride. Time at temp: heating to/cooling from $1600^{\circ} \mathrm{C}$, no holding, atmosphere: argon.

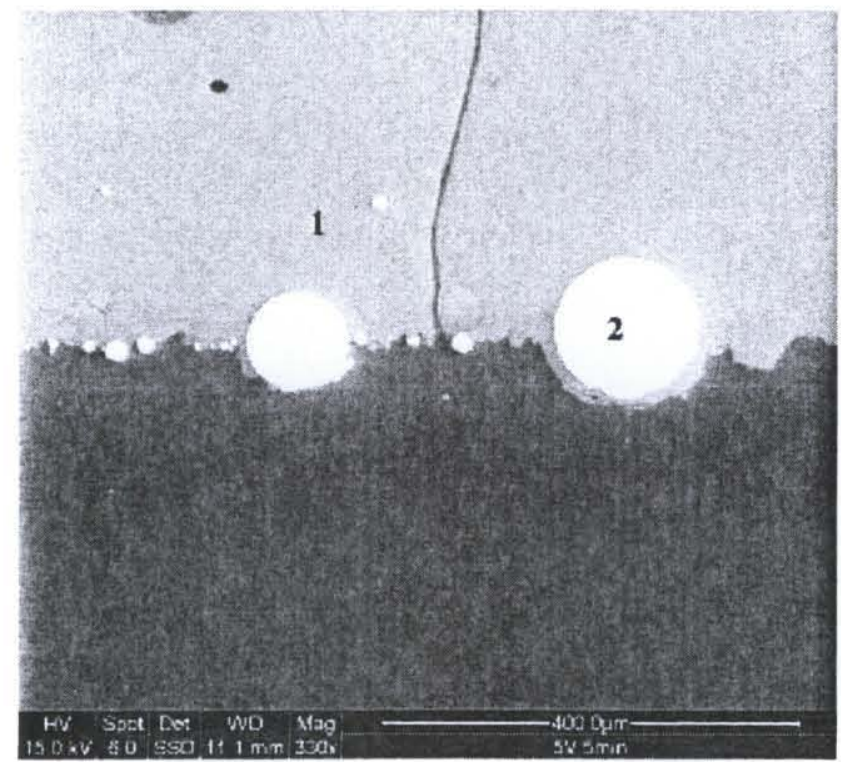

Figure 17. SEM micrograph of sample \#11 boron nitride. Time at temp: heating to/cooling from $1600^{\circ} \mathrm{C}$, no holding, atmosphere: argon. Composition of marked locations is shown in Table 8. The sample was uncoated. Scans of the base material did not yield significant results as the atomic numbers of the constituent atoms are so low. 
Table 8. EDS results for sample \#11.

\begin{tabular}{ccccc}
\hline \multirow{2}{*}{ Element } & \multicolumn{2}{c}{ Scan 1 } & \multicolumn{2}{c}{ Scan 2 } \\
& Wt \% & At \% & Wt \% & At \% \\
\hline $\mathbf{C}$ & 6.75 & 11.47 & 5.43 & 15.24 \\
$\mathbf{N}$ & -- & -- & 5.2 & 12.51 \\
$\mathbf{O}$ & 40.87 & 52.1 & 6.09 & 12.84 \\
$\mathbf{N a}$ & 0.85 & 0.76 & -- & -- \\
$\mathbf{M g}$ & 4.55 & 3.81 & 1.52 & 2.11 \\
$\mathbf{A l}$ & 13.21 & 9.98 & 3.22 & 4.02 \\
$\mathbf{S i}$ & 22.84 & 16.59 & 9.28 & 11.13 \\
$\mathbf{C a}$ & 9.03 & 4.59 & 1.21 & 1.02 \\
$\mathbf{C r}$ & -- & -- & 1.08 & 0.7 \\
$\mathbf{M n}$ & -- & -- & 0.19 & 0.12 \\
$\mathbf{F e}$ & 1.9 & 0.69 & 66.78 & 40.31 \\
\hline Total & 100 & 100 & 100 & 100 \\
\hline
\end{tabular}

\section{Discussion}

\section{Oxide Ceramic Performance}

From the preceding figures it is obvious that different alumina materials have different degrees of corrosion resistance. In most likelihood this is the effect of the various impurities in the material. Different manufacturers have slightly different compositions which can lead to dramatically different results. It is apparent from the series of alumina micrographs that the alumina tested in sample \#1 is the most corrosion resistant. This material was found to resist both corrosion and softening at $1600 \mathrm{C}$ for holding times in excess of the eight hours required for current electrolysis experiments. The other alumina samples tested did not exhibit nearly the resistance to interaction of sample \#1. Based upon the SEM results it is seen that the ceramic fails by dissolution into the regolith melt. Upon cooling the regolith solidified into a high alumina phase and a nearly 50-50 alumina-silica phase. There does not seem to be any other reaction taking place beyond the dissolving of the substrate.

Other oxide ceramics tested were found to have less than satisfactory performance. All zirconia samples had compatibility issues which prevented them from being assessed as possible containment materials. Both the calcium oxide and yttrium oxide stabilized zirconia samples exhibited intergranular corrosion of the surface exposed to the regolith melt. This corrosion layer is shown in Figure 6. the yttrium stabilized zirconia performed better than the calcium stabilized zirconia but still suffered from the formation of a weak, porous layer, in addition to exhibiting poor thermal shock resistance.

The magnesia stabilized zirconia sample had such a high degree of porosity that it absorbed the entire weight of the simulant placed upon it. Both magnesia ceramics tested were found to be inadequate. The sample which was highly porous again absorbed the 
simulant, implying that this material would be ineffective for containment. The other magnesia sample had a low degree of porosity, but was heavily corroded by the regolith at the air-melt interface eliminating it as a candidate.

Chromia-alumina refractories are known to produce hexavalent chromium compounds when heated in contact with alkali oxides ${ }^{\text {xiii }}$. Since the regolith simulant contains a small degree of sodium and potassium oxides it is expected that this reaction should occur. Chromia refractories are also known to produce volatile chromic acid, $\mathrm{CrO}_{3}$, which has the potential for contaminating the lab atmosphere ${ }^{\text {xiv }}$. For these reasons tests using the chromium aluminum oxide ceramic have been delayed until appropriate equipment and procedures for handling the hexavalent chromium compounds are determined.

Based upon the comparative performance, the best oxide tested is the alumina sample \# 1 . At this time it is the best choice for molten regolith containment.

\section{Non-Oxide Ceramic Performance}

The performance of non-oxide ceramics under oxidizing conditions is an important consideration to be made in determining their value for use as materials handling components. Given the high thermal conductivity and low thermal expansion of hot pressed boron nitride it has high resistance to thermal shock. It is therefore desirable to use as a component in a materials handling system. Because the maximum manufacturer listed temperature for the samples tested was only $850^{\circ} \mathrm{C}$ there was concern that oxidation would be considerable. However, results from testing show that even after exposure to air at $1600^{\circ} \mathrm{C}$ for 6 hours, the oxidation loss was only $0.4 \mathrm{~mm}$. As can be seen in Figure 8 the solidified regolith has a high contact angle, meaning that the melt did not wet the substrate. Additionally the interface between melt and substrate remained strongly defined suggesting limited interaction. In the figures small precipitates of a corrosion product are visible. Based upon EDS results, these precipitates are a reduced metallic component of the silicon and iron oxides in the regolith. The maximum depth of penetration of the corrosion, however, is only $56 \mu \mathrm{m}$. This implies that boron nitride could be a potential material for use in thermal shock susceptible applications, provided exposure to high partial pressures of oxygen is limited.

Silicon carbide is known to have good high temperature oxidation resistance because of the formation of a silicon dioxide layer. However, in contact with the melt in air it was seen that a large amount of oxidation took place. This was due to the fluxing action of the melt removing the protective glassy layer from the surface of the substrate. In Figure 7 a sample of silicon carbide is shown which is coated with a foamy white substance. It is believed that this substance is simply foamed regolith, which foams due to the formation of $\mathrm{CO}$ bubbles at the melt-substrate interface. This foam layer was not observed in the sample that was tested in an inert atmosphere. As can be seen in Figure 14 and Figure 15, the silicon carbide does react to form a silicon carbide- iron carbide product as EDS analysis suggests. There is also an interfacial reaction layer high in carbon. The pitting corrosion exhibited in both silicon carbide samples could be problematic if the material is exposed to the regolith melt for extended periods. However, under anticipated usage, 
(brief exposure during extraction only) there will likely not be enough exposure time to result in early failure.

It is apparent from comparing the contact angles of solidified beads (Figure 3, Figure 7 and Figure 8) that silicon carbide is not wetted by the melt to the degree of the oxides; however it is wetted more than the boron nitride samples. If a limited degree of oxidation and reaction with the melt is permissible, silicon carbide as well remains a viable material for components exposed to the regolith.

While both of these materials exhibit resistance to the oxide, and are known to exhibit resistance to metals, they are still limited by their susceptibility to oxidation. This means that a crucible which would be continuously exposed to not only the regolith and metals, but also oxygen gas, would need to be of another material. The non-wetting limited reactivity behavior however is encouraging for the use of both boron nitride and silicon carbide as materials for tubes or molds which would have to withstand contact and extreme thermal shock but would not necessarily need to be exposed to oxygen continuously.

In order to determine how oxygen partial pressure affects reactions between the melt and substrate, as well as oxidation rate, it is desirable to run a series of tests at varying oxygen pressures to measure its influence. These tests are currently in progress.

\section{Conclusions}

A series of experiments were conducted to determine the compatibility of a range of ceramic materials for containment of molten lunar regolith. Using NASA simulant JSC-1, spot contact tests were conducted for a range of times at $1600^{\circ} \mathrm{C}$. It was found that of the oxide ceramics tested, a $99.6 \%$ alumina performed the best interacting little with the melt and resisting bulk deformation for tests ranging up to 8 hours of contact in an air atmosphere. It was also found that silicon carbide and boron nitride exhibited little interaction with the melt in both air and argon atmospheres. Of these two non-oxides, high purity hot pressed boron nitride showed smaller penetration of corrosive products and considerable oxidation resistance. The protective glass that formed over silicon carbide was dissolved by the melt allowing further oxidation. Both of these however remain viable containment materials if exposure to oxygen is kept low. Chromiumaluminum oxide refractories were obtained but not tested due to their known tendency to form highly toxic by-products when in contact with compositions similar to that being tested.

\section{References}

'Curreri P. et. al. "In Situ Resource Utilization-Molten Oxide Electrolysis", MSFC Independent Research and Development Project No. 5-81, NASATTM-2006-214600 (August 2006).

ii Private correspondence, D. Sadoway, PowerPoint- "Direct Electrolysis of Molten Lunar Regolith to Produce Oxygen" (December 2007).

iii McKay D. S. et al. "JSC-1 A New Lunar Soil Simulant" Engineering, Construction, and Operations in Space IV, American Society of Civil Engineers p.857-866 (1994). 
iv Papike J.J., Simon S.B., and Laul J.C. "The lunar regolith: chemistry, mineralogy and petrology", Rev. Geophys. Space Phys., 20, pp. 761-826 (1982).

'Lay, L.A. Corrosion Resistance of Technical Ceramics, PUBLISHING HOUSE? (1983).

vi Sundaram, S.K., J. Hsu, R. Speyer, "Molten Glass Corrosion Resistance of Immersed Combustion-Heating Tubes in Soda-Lime-Silicate Glass", J. American Ceramic Society 77 [6] 1613-23, (1994)

vii Sundaram, S.K., J. Hsu, R. Speyer, "Molten Glass Corrosion Resistance of Immersed Combustion-Heating Tubes in E-Glass", J. American Ceramic Society 78 [7] 1440-46, (1995).

viii Hunt, A. , Chinn, R., "A Ceramographic Evaluation of Chromia Refractories Corroded by Slag"; Office of Science and Technical Information, USDE (2002)

${ }^{i x}$ Bennet, J. et al. "An Analysis of the Causes of Failure in High Chrome Oxide Refractory Materials from Slagging Gasifiers," Office of Science and Technical Information, USDE (2005)

${ }^{x}$ Wuchina E. et al. "UHTCs: Ultra High Temperature Ceramic Materials for Extreme Environment Applications" ??????????

${ }^{x i}$ Hot-Pressed Boron Nitride Shapes; Momentive performance materials, 2007. May 23, (2008)

xii Deal B., and A. Grove, J. App. Phys., 36, 3770 (1965).

xiil. Khoroshavin L. B. et al. "Hexavalent Chromium in Refractories" East Institute of Refractories. Translated from Ogneupory No. 9 p. 7-11, (Sept 1993)

xiv Caplan D. and M Coehen, "The Volatility of Chromium Oxide", J. Electrochemical Society. 108, 438 (1961). 